\title{
Warm Ischemia During Surgery
}

National Cancer Institute

\section{Source}

National Cancer Institute. Warm Ischemia During Surgery. NCI Thesaurus. Code C94838.

A procedure to keep a tissue or organ at body temperature while the blood supply at that site is temporarily decreased or cut off during surgery. 